This paper is currently available on line, in pre-print format, and should therefore be cited as follows:

Pickering, C., Grignon, J., Steven, R., Guitart, D. and Byrne. J. (2014). 'Publishing not perishing: How research students transition from novice to knowledgeable using systematic quantitative literature reviews', Studies in Higher Education. DOI: 10.1080/03075079.2014.914907

Once the hard copy is published, please include the relevant volume and page numbers.

\title{
Publishing not perishing: How research students transition from novice to knowledgeable using systematic quantitative literature reviews
}

Catherine Pickering ${ }^{*}$, Julien Grignon, Rochelle Steven, Daniela Guitart and Jason Byrne

Environmental Futures Research Centre, Griffith University, Gold Coast, QLD 4222, AUSTRALIA.

Emails: c.pickering@griffith.edu.au, jason.byrne@griffith.edu.au

Phone $61(0) 755528059$

* Author for correspondence: Catherine Pickering 


\begin{abstract}
Current understandings suggest that three aspects of writing practice underpin the research student publication process: knowledge creation, text production and identity formation. Publishing a literature review is the first opportunity most students have to publish. This article compares the pedagogical benefits of different literature review methods. It discusses why narrative reviews are challenging for novices both in terms of process and outcomes (publications) whereas other types of reviews, such as meta-analyses, are the province of multi-skilled teams working intensively for extended periods. Case studies are used to highlight how a new systematic quantitative literature review method, developed for the social and natural sciences, is beneficial as students can more readily create knowledge, produce text, and so transition from novice to knowledgeable and publish rather than perish.
\end{abstract}

Keywords: narrative literature review; meta-analysis; PhD students; postdoctoral study.

\title{
Introduction
}

Academics and academic institutions are increasingly evaluated on their publication outputs using a range of indices (Lawrence 2003; Linton et al. 2011; Shelton et al. 2009). Various measures of performance and impact now allow the ranking of intellectual capital, and of individuals competing for limited funding and employment (Fanelli 2010; Nicolini and Nozz, 2008; Young et al. 2008). For this reason, there is now considerable pressure in academia not only to publish, but to publish in high-ranking journals (Bretag 2012; King 2004). This focus on publication is not limited to established researchers; institutions are increasingly encouraging, supporting, and in some cases, requiring research higher degrees students to publish during their candidature (Aitchison et al. 2012), because it increases the standing of the student, their supervisors, and the institution. A publication track record is also mandatory 
for early-career researchers in many disciplines, and affects their ability to secure their first academic position (Robins and Kanowski 2008; Wilson 2002). Because literature reviews are often the first output of researchers new to a field (Green 2009), methods that facilitate research students to adopt best practice in writing, and which result in publications, have become increasingly valuable.

Literature reviews in the social and natural sciences, particularly those within a positivist paradigm, involve compiling and evaluating existing knowledge in a given field of research (Petticrew and Roberts 2006). They generally have three functions: (i) identifying, summarizing and critiquing current theory and methods; (ii) identifying ontological, epistemological and methodological problems and gaps; and (iii) providing much-needed evidence for decision-makers when identifying and supporting priority issues - especially through funding for policy development (CEBC 2010; Davies 2000; Green et al. 2006; Hammersley 2001). Undertaking and publishing literature reviews demonstrates an author's expertise and contributes directly to improving their performance and reputation in the academic community, and hence contributes to their identity as experts in their discipline (Kamler 2008; Linton et al. 2011; McGrail et al. 2006; Robins and Kanowski 2008). The publication of literature reviews is therefore important and such reviews often are highly cited research outputs. But for novice and early career researchers, literature reviews can also be daunting and difficult to write. We need better methods for undertaking such reviews if students are to master this important research skill and publish their findings.

\section{Context of literature reviews within research writing practice}

Paralleling this emphasis on publication, is increasing interest in, and reflection on, the process of academic research writing, including writing by research students (Aitchison and Lee 2006; Aitchison et al. 2012; Kamler 2008; MacLeod et al. 2012; Robins and 
Kanowski 2008). But there are some important constraints to research student writing practices. Such constraints include motivation, confidence, training and support (Kamler 2008). Some challenges arise around the multi-tasked nature of student research programs. These challenges include keeping up with the literature, formulating effective research questions, designing an appropriate methodology, undertaking the actual research, writing chapters and papers, and presenting work at conferences. The complexity of these tasks can lead to 'task confusion', slowing the progress of the student and hampering learning.

Others challenges arise from a divergence in understandings of the roles, responsibilities and capacities of supervisors to mentor research students in writing for publication (Aitchison et al. 2012; Kamler 2008). For example, disciplines vary in assumptions about when supervisors will co-author research student publications - affecting the amount and type of mentoring students may receive (Kamler 2008; Robins and Kanowski 2008). Even within a single discipline, supervisors' approaches to writing for publication vary widely - differing in mentoring style, amount of mentoring, and whether they even mentor research higher degree students' writing (Aitchison et al. 2012). Support outside of the student-supervisor relationship also varies within and among institutions (Aitchison et al. 2012). Institutional support can include peer writing groups/retreats, books, training programs or workshops and learning support units/staff (Aitchison and Lee 2006; Aitchison et al. 2012; Kamler 2008; MacLeod et al. 2012). The patchy attention to student writing can be a source of anxiety and despondence.

Negative emotional responses to writing practice, including experiencing inappropriate feedback, include anxiety, depression and fear (Aitchison et al. 2012; Kamler 2008; MacLeod et al. 2012). Students often experience these feelings when writing, but they can occur even when students think about writing, and they can become a major impediment to publishing (Aitchison et al. 2012; Kamler 2008; MacLeod et al. 2012). The success of 
strategies intended to assist students and others in publishing is due, in part, to how well those strategies enable students to address writing-related anxiety and the high emotional load involved in the publication process (Aitchison and Lee 2006; Aitchison et al. 2012; MacLeod et al. 2012).

There is an ongoing debate about the process and complexity of writing, especially by research students, and about academic literacy more generally (Aitchison and Lee 2006; Aitchison et al. 2012; Lea 2004; Lea and Street 1998). Increasing attention is being given to the role of writing as knowledge creation, the complexity of writing practice, academic socialisation, and more broadly to the role of academic literacy as 'meaning-making' and contested territory within an academic literacies paradigm (Aitchison and Lee 2006; Aitchison et al. 2012; Lea 2004; Lea and Street 1998). While we acknowledge the importance of this broader discourse, this paper focuses on a specific aspect of research student writing practice: writing and publishing literature reviews by novices. It does so within a theoretical pedagogical structure derived from Aitchison and Lee (2006), who have examined research writing group participant experiences to illustrate broader issues to do with research writing. Our paper therefore, contextualises the publication of literature reviews in terms of the three aspects of the same process of research student writing: knowledge creation, text production and identity-formation (Aitchison and Lee 2006). We also employ a similar approach to Aitchison and Lee (2006) and Kamler (2008), by presenting case studies to illustrate more general issues about research writing practice. Like Robins and Kanowski (2008) this involves research students and supervisors as joint authors of this text, providing a fuller expression of research student writing as a social practice.

Literature reviews provide a particularly powerful context to examine research student's writing practice. They are often the first step in the student's experience of academic literacy, and configure both the research thesis and potential future publications. 
Literature reviews require students to engage in the social practice of academic writing, within a student-supervisor relationship. Literature reviews also require research students to create knowledge, even if this may be summative. They require students to produce text, which is different in style and depth to their past experiences as undergraduates, and writing such a review entails assimilating discipline norms about the form and style of such documents. The writing process often involves a transition from 'university student' to 'research student', and from 'novice' to 'knowledgeable scholar', well versed in both their discipline and the specific topic of their research. Successfully negotiating this process is critical in students' early stages of identity formation as emergent 'researchers'.

To situate our case studies, we overview three different types of literature review methods, including systematic quantitative literature reviews. We give specific attention to how they contribute to the process of knowledge creation, text production and identityformation. We then illustrate these three aspects of the practice of research writing using three case studies: an undergraduate student (Steven), an honours student (Guitart) and an early career researcher (Grignon). All three of these students have used a systematic quantitative literature review method to evaluate diverse and emerging knowledge areas, and have produced and published academic texts. They have reported that this new method assuaged many of their anxieties associated with writing and enabled them to see themselves as effective writers and scholars.

\section{Different literature review methods}

There are a range of methods used for literature reviews within the social and natural sciences (Table 1). Each method provides different experiences in knowledge creation, text production and identity formation. Traditional narrative literature reviews for example, typically involve authors using their own judgment to select representative literature, assess 
its relative importance, and present their findings as a carefully argued narrative (Green et al. 2006; Hammersley 2001; Randolph 2009) (Table 1). Such reviews rely primarily on the author's understanding and assessment of the field and often emphasise what is known, rather than what is not known (Collins and Fauser, 2005; Petticrew 2001). This type of literature review is usually undertaken by scholars who not only self-identify as experts in the field, but are also acknowledged as such by their peers (Borenstein et al. 2009; Green, 2009). Although this method is commonly used for literature reviews undertaken by research students, the reviews they produce are rarely published because the method has several disadvantages for research students (Kamler 2008; Pickering and Byrne in press; Randolph 2009; Robins and Kanowski 2008).

The first disadvantage with this type of review is that the method used for knowledge creation is internalised and selective, rather than standardised, reproducible and transparent (Petticrew and Roberts 2006). Text production involves a narrative style, which can differ from norms for more traditional research papers in disciplines that follow a standardised format (e.g. abstract, introduction, methods, results, discussion and conclusions). Therefore research students may need to master one style of writing for the literature review, and a different style for their other chapters/publications, which are based on their own research. Identify-formation using this method can be challenging, particularly if the research student attempts to publish the review. Because this method is reliant on the recognition of the writer(s) as expert(s), students may perceive and experience the process as 'a bridge too far'. For instance, the narrative method requires intimate familiarity with the field of knowledge to provide the authority and capacity to evaluate different studies using personal criteria that may not even be described in the resulting review (Petticrew and Roberts 2006; Randolph 2009). 
Systematic literature reviews are a second example. These reviews differ from most narrative literature reviews in the method of knowledge creation. Hence they more easily fit within a positivist paradigm, because the methods used to identify and select literature are explicit, reproducible and without a priori assumptions on the relevance of the literature selected (Cochrane Collaboration 2012; Petticrew and Roberts 2006; Pickering and Byrne in press). As such, these reviews are more comprehensive, have fewer biases in identifying the current status of knowledge (CEBC 2010, Cochrane Collaboration 2012; Petticrew and Roberts 2006) (Table 1). However, such systematic reviews frequently address quite narrowly defined research questions, and are not suitable for some types of literature (Borenstein et al. 2009; CEBC 2010, Cochrane Collaboration 2012; Petticrew 2001). Systematic literature reviews can be further separated into three methods: quantitative (Pickering and Byrne in press), weighted (CEBC 2010; Petticrew and Roberts 2006) and meta-analysis (Cochrane Collaboration 2012; Petticrew and Roberts 2006) based on the extent which they rely on quantitative or statistical analysis of data within the papers reviewed (Table 1).

Well recognised examples of systematic literature reviews, where different studies are weighted based on a range of criteria, often involve meta-analysis. They include the Cochrane Reviews within health science and allied fields (Cochrane Collaboration 2012; Higgins and Green 2009) and Campbell reviews of social interventions within education, crime and justice, and social welfare fields (Campbell Collaboration 2012). Similar approaches are being promoted in other disciplines including conservation and environmental management (CEBC 2010). The Cochrane Reviews originally focused on comparing randomised control trails, and are considered the 'gold standard' for evidence based decision making within the health disciplines (Higgins and Green 2009). More recently, Cochrane Reviews have also included clinical controlled trials and non-randomised observational studies where appropriate (Higgins and Green 2009). 
Similarly, Campbell Reviews use a systematic method for collecting data, and where possible, perform meta-analysis (Campbell Collaboration 2012). Undertaking these types of reviews is complex, and requires diverse groups of skilled experts (including those familiar with specific weighted criteria) to evaluate different studies and the statistical methods involved in meta-analysis (Higgins and Green 2009; Petticrew and Roberts 2006) (Table 1). In the case of the Cochrane Reviews, they explicitly exclude reviews undertaken by one person, requiring teams of experts to work together (Higgins and Green 2009). Therefore these types of reviews may not be suitable for research students because knowledge creation is highly complex, text production entails teamwork, and identify formation is predicated on technocratic expertise.

\section{The systematic quantitative literature review method}

A more recently developed systematic quantitative literature review method sits between the more traditional narrative and systematic weighted methods (Pickering and Byrne in press) (Table 1). Knowledge creation using this method involves systematically searching for existing literature using key search words to identify papers for inclusion, based on clearly articulated reproducible criteria, similar to that in other systematic methods (Figure 1). However, the types of research included can be broader than those used in meta-analysis and include methods from the social as well as natural sciences (Guitart et al. 2012, Pickering and Byrne in press; Roy et al. 2012). These types of reviews can include knowledge generated though both qualitative techniques (e.g. interviews, content and text analysis, case studies, observations and focus groups), as well as quantitative approaches (e.g. questionnaire surveys, field-surveys and samples, remote sensing and satellite imagery, field experiments, laboratory experiments including randomised control trails) (Guitart et al. 2012, Pickering and Byrne in press; Roy et al. 2012). Data for each paper that fits the pre-determined 
selection criteria is entered into a personal database. This data includes bibliographic information, details of the location of the research, the methods used, the subjects of the research, the response measured, and the results obtained (Figure 1). This data is then quantified to assess the scope, depth and breadth of research on a topic. The major difference between this method and narrative reviews is that it produces knowledge about 'what we know' as well as 'what we don't know' by identifying research trends and gaps.

Because this type of review is systematic, quantitative and analytical, such literature reviews give research students a different experience, grounding students in knowledge creation, scaffolding them in text-production, and acculturating them into scholarly research methods, techniques, processes, attitudes and values (Pickering and Byrne in press). The straightforward step by step process underpinning this method dramatically reduces the time, effort and expertise traditionally required by other methods (Figure 1). The systematic quantitative literature review method is also particularly useful for trans-disciplinary research, because different aims, methods, data collected and analyses can all be included (Guitart et al. 2012; Pickering and Byrne in press; Roy et al. 2012). Furthermore, its flexibility makes the method accessible to researchers new to a field and for multidisciplinary topics.

Text production can also be much simpler than for narrative reviews, because the systematic review uses a simpler structure (i.e. abstract, introduction, methods, results and discussion) (Figure 1) which emerges from the way data is collected and analysed. Most importantly, the method allows research students to become familiar with the discipline by reviewing previous research that directly relates to their topic. The process of writing such a review makes students consider the efficacy of alternative methodologies and enables them to think critically about methodological, geographic and topical lacunae in research knowledge, thus helping students to identify gaps that their own work might begin to address. In this way 
the systematic review helps students to 'map their discipline' while simultaneously enhancing their identify formation as knowledgeable scholars, with the added benefits of creating new knowledge.

\section{Case studies}

To illustrate the process involved in undertaking a systematic quantitative literature review and its benefits, we draw upon the experiences of three student authors who have used this method. We illustrate how they applied each of the 15 steps involved in review, and reflect on this process in relation to knowledge creation, text production and identify formation.

\section{Case study 1: a third year undergraduate research student}

This first case study presents the reflections of an undergraduate student (Steven) on her the systematic quantitative review method and how she used this method to review research on the impacts of nature based tourism on birds. At the time she undertook the review, she was an undergraduate completing the third year of a Bachelor of Science at an Australian University. She undertook the review as part of a small supervised research project that required approximately four weeks of full time work spread out over 16 weeks (e.g. one out of four courses undertaken during one semester of an Australian academic year).

The first step of the process was defining the topic. The review was within the general field of recreation ecology which assesses the environmental impacts of different tourism and recreation activities. Her review focused on birds as they are important components of biodiversity and play a key role in many ecosystems. Additionally, when examining the effects of disturbance on natural systems, birds are considered useful indicators as they are abundant and easily observed. The review focused on non-motorised recreation and tourism 
activities as they are perceived to have fewer impacts, and so can be permitted in areas of high conservation value including Word Heritage and other parks.

In Step 2, she formulated her research questions, which were: 1) what methods were used to detect effects on birds?; 2) which species/families of birds were assessed?; 3) what were the responses of the birds?; 4) where was research conducted?; and 5) conversely, which locations, habitats and bird taxa have not been assessed?. In Step 3 she selected the following keywords for the database searchers: 'bird' in combination with; 'trail', 'track', 'walking', 'hiking', 'impact', 'disturbance', 'mountain bike', 'effect', 'dog walking', 'horse riding', 'ecotourism', 'tourism' 'recreation'. In Step 4 she selected and searched large, wellrecognised and comprehensive databases of scientific research: specifically Web of Science, Google Scholar and Science Direct. In Step 5 she read and assessed publications identified from the databases. This involved an initial screening of publications based on the article titles and abstracts to exclude duplicate papers, grey literature and review papers. Papers were only included if they fitted the following criteria: original science research papers published in peer reviewed English language science journals that assessed the environmental impacts of some type of non-motorised nature based tourism activity on birds. Review articles, books, book chapters and grey literature (reports, conference proceedings, etc) were excluded as she only wanted to include the results of original research that had been peer reviewed, and hence the methods, analyses and conclusions of the studies were deemed by academic reviewers of internationally recognised scientific journals to be of a suitable quality for inclusion in the journal.

To double check that the review was comprehensive, the reference lists of reviews and original research papers were used to ensure that all relevant papers were identified including papers that may predate inclusion in electronic databases. For all papers that passed initial screening, the student then double checked if they fitted the above criteria by carefully 
reviewing the full text of the papers, with 69 papers identified that satisfied all the criteria. Steps 6 to 9 were iterative, involving developing and refining a series of categories used to include information about the papers and enter data for each of the 69 papers. A total of 63 categories and subcategories were used to record information about the publication (when, where published and by whom), the birds (which species, guilds, conservation status of birds), the study location (geographical location, if it was conducted in a conservation reserve, climatic region, habitat type), the methods used (observation, experimental, etc.), the recreation activities and the bird responses measured (changes in individuals, population and/or reproduction and if the response was positive, neutral or negative).

In Step 10, the student was able to use this data to produce summary tables highlighting how many studies have been conducted, where, using what methods, on what birds, the response of the species. She also drafted the methods she used (Step 11) and based on these tables evaluated the key results of the review (Step 12). She was able to document the full range and types of research on this topic including which types of recreational activities had been assessed, what type of impacts they had, and which types of birds were impacted. She also demonstrated where there are knowledge gaps, including about particular activities, birds and locations. For example, the student found that many areas with high bird diversity, which are popular destinations for nature based tourism, have received limited or no attention in the academic literature. She drafted, revised and submitted the paper (Steps 13-15), which was published in an international peer reviewed journal (Steven et al. 2011).

In addition to creating new knowledge for the research field, her review contributed to personal knowledge creation. She learned about the different hypotheses, methods and approaches that have been used, which helped her develop her own research agenda. The structured nature of the results obtained through the systematic quantitative literature review method made the text production much easier. Hence the storyline of the text was clear from 
the beginning, facilitating the writing of the review. The process of reviewing the literature and writing for publication also gave her insight into the life of a scientific researcher; that is, it helped her identity formation as an academic.

\section{Case study two: an Honours student}

The second case study illustrates the experience of a novice researcher (Guitart) who, at the time, was a fourth year Honours student completing her Bachelor of Science at an Australian University. The Honours program involved nine months of intensive research, with two months allocated to the literature review. Her honours research was co-supervised by a botanist (natural scientist - Pickering) and an urban geographer (social scientist Byrne), two academics from quite different disciplines with different scholarly training and practices.

The first step in this review involved defining the topic, which was assessing the current status of research on urban community gardens. Background reading prior to commencing the review indicated that was variation in the use of the term 'community gardens' in the literature, so the student had to clarify and justify how the term would be used in the review. In Step 2, the student defined her research questions. Specifically she wanted to determine the current extent of the academic literature on community gardens including (i) who has undertaken research; (ii) where was it is published; (iii) where were the gardens studied; (iv) and what the types of methods were used. She also examined the characteristics of the gardens including what is grown, by whom, and who owns the land and what has been written about the motivations, benefits and limitations of community gardens. In Step 3 she selected the following keywords 'community garden' and a combination of terms including: 'space', 'green', 'gardening', 'school', 'urban', ‘food production', 'land use', 'place', 'planning', 'agriculture' and 'people'. As the community garden literature is broad the student 
selected database that would cover a diverse academic literature and hence in Step 4 she searched the electronic databases: Google Scholar, Geo Base, ISI Web of Knowledge, Pro Quest and Bio Med. To ensure that the review was comprehensive, reference lists from papers including in a recent annotated bibliography of community gardens were cross checked with papers identified from searchers of the databases.

Step 5 involved an initial screening of potential papers for inclusion, based on the article titles and abstracts, followed by a more detailed assessment of those articles that passed initial screening. This involved reading the article in detail, including the aims, methods and results sections. The criteria for inclusion of a paper in the review was that it had to be (i) original research published in a peer reviewed English language journal, (ii) and that it was on urban community gardens and not backyard, home gardens or rural community gardens. Again the review did not include books, book chapters or grey literature, and all papers included were assessed in detail or the appropriateness of the methods used to collect data, the types of analysis used and the conclusions drawn. A total of 87 papers fitted all the criteria and hence were included in the database.

Step 6 involved structuring the database to include categories and subcategories on the paper, the general discipline area and general focus of the paper, the information obtained about the gardens and who was running them, and the types of methods used to obtain that information. Information about the motivations, benefits and challenges involved in the gardens was also recorded, including if these were just discussed or if these factors were also demonstrated by the research presented in the paper.

Because this literature was complex, there was considerable work involved in structuring, revising and entering the data. A total of 158 categories and subcategories were used to comprehensively and accurately record the diversity of data encompassed in the papers. Yet, when it came to Step 10, producing and reviewing summary tables, the results 
were relatively straight forward to present. This involved producing a table and a map, highlighting where research has been conducted, and which journal disciplines conducted that research on community gardens. She also produced tables that quantified the types of methods used and the data collected on community gardens, including data about the characteristics of the gardens, the types of communities involved in the gardens, the motivations for establishing the gardens and the challenges involved in community gardens. The paper she wrote included a table that listed whether papers had discussed the different benefits of gardens or if they actually demonstrated benefits too.

From these tables the student was able to identify the key results and conclusions (Step 12), and draft the methods (Step 11). Specifically she was able to demonstrate that despite a diversity of research on community gardens, most research had been conducted on social issues, regarding the communities involved in the gardens, with limited biophysical research describing what was grown in the gardens (plant diversity), and how it was grown (gardening practices). Another major knowledge gap she identified was the limited geographical distribution of the research, with over half of the papers from the United States (USA). Moreover, within USA the research was predominately from low income areas of large industrial cities - rust belt cities. Thus she found that the conclusions drawn from current literature are likely to be biased in terms of the characteristics of these gardens and their gardeners, as well as gardeners' motivations and benefits.

The review contributed to the student's personal knowledge. She obtained a comprehensive knowledge of the field including the diverse methods used by different scholars in geography, political science, urban planning, sociology and health science. As a result she became familiar with trans-disciplinary knowledge and conversant in diverse epistemologies. The method also helped her with identity formation enabling her to positively engage with peer-reviewers of her manuscript with self-trust and confidence. 
Case study three: an experienced researcher new to a field

The third case study illustrates the experience of a researcher novice to a field but not to research. The research fellow (Grignon) with a $\mathrm{PhD}$ in marine biology had already published peer-reviewed articles in international journals. His new position involved conducting a systematic quantitative literature review of shark tourism: an overlapping area of research between marine biology, tourism and conservation. Shark tourism is an emerging, diverse field of research with a rapidly growing literature, and hence a comprehensive review was important, but had never been attempted before. The aim of the review (Step 1) was to provide an overview of the diversity, breadth and current issues in shark tourism including six key issue (Step 2): assessing the (i) economic value, (ii) geographical scale, (iii) species involved, (iv) practices/activities used, (v) potential negative impacts of the shark tourism industry, and (vi) analysing the potential benefits of shark tourism for shark conservation. The use of the systematic quantitative literature review was essential in structuring the large amount of information available about these six issues, including cross-referencing articles that address more than one issue.

Here, we present the sequence he used to review the economic value of shark tourism to illustrate the type of approach he used across all six issues. In Step 3 he identified 'shark' and a combination of 'tourism', diving', 'industry', 'economic', 'market', 'value', 'revenue', 'dollar', 'operation', 'operator', 'tourist', 'cost per trip', 'non-consumptive', 'price' as keywords. The associations of 'shark' and 'tourism' and 'shark' and 'diving' were used rather than 'shark tourism': as it is a term with limited use in peer-review papers. The databases Web of Science, Google Scholar, Science Direct and an online annotated bibliography of shark research were searched initially (Step 4) and then the reference lists in papers and reviews used to triangulate findings, thus ensuring that the review was comprehensive. In Step 5, the abstract, 
aims and methods sections of all the papers identified in Step 4 were screened. The criteria used for the inclusion of a paper were that: (i) it presents the results of a study of the economic value of shark tourism and (ii) the methods were clearly defined. Articles only providing gross estimations, those without methods and those whose data sources were absent or dubious were excluded, with 25 papers identified that fitted all these criteria.

In Step 6, the categories and subcategories used in the database were developed and used. Information entered in the personal database included the discipline area of the paper, the country, region and/or operators where the study was conducted, the date and the duration of the research, the number and the nature of the shark species studied, the type of data collected, the origin of the data collected, the presence of calculations or the reporting of summary data, the type of calculations undertaken, the presence of caveats, and the overall finding of the paper.

The production and review of summary tables (Step 10) was straight forward. Tables included information about the where studies were conducted, the economic value (converted to \$USA), the number of visitors involved in shark tourism activities, the shark species involved and when the research was conducted. Additionally, the contribution of shark tourism to the national economy and the differences between the consumptive (from fishing) and non-consumptive (from tourism) values of sharks were also demonstrated for numerous locations.

The key results and conclusions (Step 12) highlighted that shark tourism, while underrecognised, was a booming industry generating hundreds of millions of dollars (\$USA) per year, involving hundreds of thousands of tourists and several hundred operators in $>30$ countries. Furthermore, shark tourism has now become an important driver of economic development in many countries and regions and is heavily marketed by tourism destinations such as the Maldives, the Bahamas and Thailand. The review highlighted differences between 
the non-consumptive and consumptive values of sharks, providing additional economic support for recent bans on shark fishing in many countries.

The literature on shark tourism was scattered among papers published in a range of disciplines including ecotourism, ecology, economics and management. The use of a systematic search methodology was essential to identify the diverse literature. It allowed the rapid production of a literature review that would otherwise have been very difficult, if not impossible, for a researcher new to a field. The method also enabled him to write a clearlystructured paper, which is favoured by international peer-reviewed science journals, thus improving his chances of publication.

\section{Discussion and conclusions}

Universities are coming under increasing pressure to demonstrate that they are producing research that is of the highest quality, and addresses important societal concerns. Disseminating research and demonstrating its impact, depends upon the timely publication of research papers. Many universities also expect their higher degree research students to publish including in well-ranked journals before they graduate. While institutional support for research students to publish is growing, effective mentoring of students is often patchy. Consequently students can become anxious about writing, leading to despondency which may block progress if not managed. The success of strategies intended to assist students and others in text production (especially publishing) now depends upon how well strategies enable students to address writing-related anxiety and how well those strategies scaffold knowledge creation and identity formation.

A literature review is often the first formal writing project undertaken by research students. While literature reviews can be published, and are often highly-cited, traditional review methods make this very difficult for novices. These methods either require a mastery 
of the literature that only an expert can attain, or they rely on team analysis of published datasets, which is not possible for most research students. But a new type of review methodthe systematic quantitative review - is showing promising results including in text production, knowledge creation and identity formation.

The systematic quantitative literature review method has been demonstrated to provide a range of practical benefits for new researchers. Firstly, and potentially most importantly, it allows new researchers to conduct and publish literature reviews despite being new to research, new to a discipline, or inexperienced in inter-disciplinary research. We have shown in this paper that a variety of 'new' researchers have used this method to make important contributions to knowledge creation in their respective disciplines, within a relatively short time frame and without a multi-disciplinary team, extensive funding support, or familiarity with the detailed methodologies required for meta-analysis type reviews (Higgins and Green 2009; CEBC 2010).

The experiences of student researchers that we have discussed here also involved becoming personally knowledgeable about their disciplines and about the process of undertaking research within those disciplines. Using this new type of literature review method, they found text formation straight forward and relatively easy, even when they had no previous experience in research writing practice and publication. They all felt that using the method transformed them from novices to knowledgeable in the disciplines, capable of making contributions including identifying research gaps, and then undertaking their own research to begin to address these lacunae in the research. Based on our collective experience, we feel the systematic quantitative literature review method should be more widely used by the scholarly community, including research students so more of them flourish and publish.

\section{Acknowledgments}


We thank Clare Morrison, and an anonymous reviewer for providing comments on this manuscript.

\section{References}

Aitchison, C. and Lee, A. 2007. Research writing: problems and pedagogies. Teaching in Higher Education 11: 265-278.

Aitchison, C., Catterall, J., Ross, P. and Burgin, S. 2012. 'Tough love and tears': learning doctoral writing in the sciences. Higher Education Research and Development 31: 435 447.

Borenstein, M., Hedges, L.V., Higgins, J.P.T. and Rothstein, H.R. 2009. Introduction to Metaanalysis. London: Wiley.

Bretag, T. 2012. Publish or perish: Ramifications for online academic publishing. In Misbehaviour Online in Higher Education, eds. L.A. Wankel and C. Wankel, 11-24. Emerald Group Publishing Limited: London.

Buckley, R. 2004. Impacts of ecotourism on birds. In Environmental Impacts of Ecotourism, ed. R. Buckley, 187-209. Cambridge: CAB International.

Centre for Evidence Based Conservation, CEBC. 2010. Guidelines for systematic review in environmental management. Version 4.0. Environnemental Evidence: www.environmentalevidence.org/Authors.htm. Last accessed November 2012.

Campbell Collaboration 2012. Campbell Reviews, http://www.campbellcollaboration.org/about_us/index.php. Last accessed November 2012.

Cochrane Collaboration 2012. Cochrane Reviews. http://www.cochrane.org/cochranereviews. Last accessed November 2012.

Collins, J.A. and Fauser, B.C.J.M. 2005. Balancing the strengths of systematic and narrative reviews. Human Reproductive Update 11: 103-104.

Davies, P. 2000. The relevance of systematic reviews to educational policy and practice. Oxford Review of Education 26: 356-378.

Fanelli, D. 2010. Do pressures to publish increase scientists' bias? An empirical support from US States data. PLoS ONE 5: e10271.

Green, B.N., Johnson, C.D. and Adams, A. 2006. Writing narrative literature reviews for peer-reviewed journals: secrets of the trade. Journal of Chiropractic Medicine 5: 101117. 
Green, R. 2009. American and Australian doctoral literature reviewing practices and pedagogies. Doctor of Philosophy Thesis, Melbourne: Deakin University.

Guitart, D., Pickering, C.M. and Byrne, J. 2012. Past results and future directions in urban community garden research. Urban Forestry and Urban Greening 11: 364-373.

Hammersley, M. 2001. On 'systematic' reviews of research literatures: A 'narrative' response to Evans and Benfield. British Educational Research Journal 27: 543-554.

Higgins, J.P.T. and Green, S. (eds.) 2009. Cochrane handbook for systematic reviews of interventions. Version 5.0.2. The Cochrane Collaboration. Available from www.cochrane-handbook.org

Kamler, B. 2008. Rethinking doctoral publication practices: writing from and beyond the thesis. Studies in High Education 33: 283-294.

King, D.A. 2004. The scientific impact of nations: what different countries get for their research spending. Nature 430: 311-316.

Lea, M.R. 2004. Academic literacies: a pedagogy for course design. Studies in Higher Education 29: 741-756.

Lawrence, P.A. 2003. The politics of publication: authors, reviewers and editors must act to protect the quality of research. Nature 422: 259-261.

Linton, J.D., Tierney, R. and Walsh, S.T. 2011. Publish or perish: how are research and reputation related? Serials Review 37: 244-257.

MacLeod, I., Steckley, L. and Murray, R. 2012. Time is not enough: promoting strategic engagement with writing for publication. Studies in Higher Education 37: 641-654.

McGrail, M.R., Rickard, C.M. and Jones, R. 2006. Publish or perish: a systematic review of interventions to increase academic publications rates. Higher Education Research and Development 25: 19-35.

Nicolini, C. and Nozza, F. 2008. Objective assessment of scientific performances world-wide. Scientometrics 76: 527-541.

Ogilvie, D., Egan, M., Hamilton, V. and Petticrew, M. 2004. Promoting walking and cycling as an alternative to using cars: systematic review. British Medical Journal 329: 763-766.

Petticrew, M. 2001. Systematic reviews from astronomy to zoology: myths and misconceptions. BMJ 322: 98-101.

Petticrew, M. and Roberts, H. 2006. Systematic Reviews in the Social Sciences: A Practical Guide. Oxford: Blackwell Publishing. 
Pickering, C. and Byrne, J. In Press. The benefits of publishing systematic quantitative reviews for $\mathrm{PhD}$ candidates and other early career researchers. Higher Education Research and Development.

Pickering, C.M. and Hill, W. 2007. Impacts of recreation and tourism on plant biodiversity and vegetation in protected areas in Australia. Journal of Environmental Management 85: 791-800.

Randolph, J. 2009. A guide to writing the dissertation literature review. Practical Assessment, Research and Evaluation, 14. Available online:

http://pareonline.net/getvn.asp?v=14\&n=13.

Robins, L. and Kanowski, P. 2008. PhD by publication: a student's perspective. Journal of Research Practice 4: 1-20.

Roy, S., Byrne, J., and Pickering, C. 2012. A systematic quantitative review of urban tree benefits, costs, and assessment methods across cities in different climatic zones. Urban Forest and Urban Greening 11: 351-363.

Shelton, R.D., Foland, P. and Gorelsky, R. 2009. Do new SCI journals have a different national bias? Scientometrics 79: 351-363.

Steven, R., Pickering, C.M. and Castley, G. 2011. A review of the impacts of nature based recreation on birds. Journal of Environmental Management 92: 2287-2294.

Wilson, K. 2002. Quality assurance issues for a $\mathrm{PhD}$ by published work: a case study. Quality Assurance in Education 10: 71-78.

Young, N.S., Ioannidis, J.P.A., Al-Ubaydli, O. 2008. Why current publication practices may distort science. PLoS Medicine, 5: 1418-1422. 